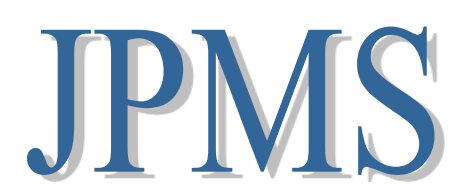

Jurnal Pengabmas Masyarakat Sehat

ARTIKEL HASIL PENGABDIAN KEPADA MASYARAKAT

URL artikel: http://ejournal.poltekkes-denpasar.ac.id/index.php/JPMS/article/view/jpms2403

\title{
Penyuluhan Tentang Bahaya Abortus Di SMA Negeri 1 Kairatu
}

\author{
Netty Taribuka ${ }^{1 k}$; Wa Ode Ningko ${ }^{1}$ \\ ${ }^{1}$ Sekolah Tinggi Ilmu Kesehatan Maluku Husada, DIII Kebidanan \\ Email penulis korespondensi $\left({ }^{\mathrm{K}}\right)$ : Taribuka@gmail.com
}

\begin{abstract}
Education on sexual and reproductive health for adolescents in Indonesia has not been fully accepted by the community. This is influenced by the complex environment of social, cultural and religious life. Many people consider that sexual and reproductive health education is a taboo subject to discuss among adolescents. These conditions make adolescents confused in determining their reproductive health behavior. However, over time, the influence of Western culture has brought freedom and open access to information so as to provide opportunities for adolescents to have negative behaviors in reproductive health. The prevalence of sexually active behavior in male adolescents $(56.6 \%)$ is higher when compared to adolescent girls (43.7\%). The problem of abortion in adolescents needs to be seriously addressed, because this problem occurs mostly in developing countries such as Indonesia due to the lack of access to information about abortion. This is evident from many studies which state that the high number of unsafe abortions that causes death is due to the lack of knowledge of young women about the dangers of abortion.
\end{abstract}

Keywords: danger of abortion.

\section{Pendahuluan}

Pendidikan kesehatan seksual dan reproduksi remaja yang ada di Indonesia belum sepenuhnya diterima oleh masyarakat. Hal ini dipegaruhi oleh lingkungan yang kompleks dari kehidupan sosial, budaya, dan agama. Banyak masyarakat menganggap bahwa pendidikan kesehatan seksual dan reproduksi adalah suatu hal yang tabu untuk didiskusikan pada remaja. Kondisi seperti ini membuat remaja menjadi bingung dalam menentukan perilaku kesehatan reproduksinya. Namun, seiring perkembangan zaman dari pengaruh budaya Barat maka membawa kebebasan dan akses informasi yang terbuka sehingga memberikan kesempatan pada remaja memiliki perilaku negatif dalam kesehatan reproduksi. Prevalensi perilaku seksual aktif pada remaja laki-laki $(56,6 \%)$ lebih tinggi bila dibandingkan dengan remaja perempuan $(43,7 \%) .{ }^{(1)}$

Pada umumnya remaja memiliki rasa ingin tahu yang tinggi (high curiousity). Remaja cenderung ingin berpetualang menjelajah segala sesuatu dan mencoba segala sesuatu yang belum pernah dialaminya. Selain didorong juga oleh keinginan menjadi seperti orang dewasa menyebabkan remaja 
ingin mencoba melakukan apa yang sering dilakukan orang dewasa termasuk yang berkaitan dengan masalah seksualitas. ${ }^{(2)}$

Seorang ahli menyatakan bahwa perilaku seks bebas terdiri dari pegangan tangan, berpelukan, perabaan daerah sensitive, ciuman, saling menempelkan alat kelamin, sampai pada hubungan intim (persetubuhan). Dengan demikian pernyataan informan tentang perilaku seks bebas sudah sejalan dengan konsep seks bebas yang dinyatakan oleh Sarwono; yang menandakan bahwa kelompok informan memahami secara benar apa yang dimaksud dengan perilaku seks bebas. ${ }^{(3)}$

Perkembangan jaman saat ini, ikut memengaruhi perilaku seksual dalam berpacaran remaja. Hal ini misalnya dapat dilihat bahwa hal-hal yang ditabukan oleh remaja pada beberapa tahun yang lalu, seperti berciuman dan bercumbu kini telah dibenarkan oleh remaja sekarang. Bahkan ada sebagian kecil dari mereka setuju dengan free sex. Kondisi tersebut cukup mengkhawatirkan mengingat perilaku tersebut dapat menyebabkan Kasus Kehamilan Tidak Diinginkan (KTD) yang selanjutnya memicu praktik aborsi yang tidak aman, penularan PMS dan HIV/AIDS, bahkan kematian. Penelitian yang dilakukan oleh Balai Besar Penelitian dan Pengembangan Pelayanan Kesejahteraan Sosial (B2P3KS), Departemen Sosial Republik Indonesia menyatakan bahwa jumlah remaja yang memiliki masalah KTD dan berkonsultasi tiap tahun mengalami kenaikan. Fakta yang ditemukan pada penelitian tersebut adalah dari populasi yang berdasarkan pendidikan, dari tahun 2002-2005, remaja yang mengalami KTD terbanyak adalah yang memiliki pendidikan perguruan tinggi yakni mahasiswi $(59,22 \%)$, remaja yang berpendidikan SMU (17,70\%) dan yang paling kecil SMP (1,63\%). Secara keseluruhan, remaja yang hamil di luar nikah terbesar terjadi pada tahun 2002 (640 kasus). Kemudian tahun 2004 sebanyak 560 kasus dan tahun 2005 sebanyak 551 kasus. ${ }^{(4)}$

Abortus adalah berakhirnya suatu kehamilan (oleh akibat-akibat tertentu) padaatau sebelum kehamilan tersebut berusia 22 minggu atau buah kehamilan belum mampu untuk hidup di luar kandungan. ${ }^{(5)}$ Masalah aborsi pada remaja perlu mendapatkan penanganan serius, karena masalah tersebut paling banyak muncul di negara-negara berkembang seperti Indonesia karena kurang tersedianya akses untuk mendapat informasi mengenai aborsi. Hal itu terbukti dari banyak penelitian menyatakan tingginya angka aborsi yang tidak aman sehingga menyebabkan kematian oleh karena kurangnya pengetahuan remaja putri terhadap bahaya aborsi. ${ }^{(6)}$

World Health Organization (WHO) memperkirakan ada 22 juta kejadian aborsi tidak aman (unsafe abortion) di dunia, ${ }^{(7)}$ 9,5\% (19 dari 20 juta tindakan aborsi tidak aman) diantaranya terjadi di negara berkembang. Sekitar $13 \%$ dari total perempuan yang melakukan aborsi tidak aman berakhir dengan kematian. Di wilayah Asia Tenggara, WHO memperkirakan 4,2 juta aborsi dilakukan setiap tahun, dan sekitar 750.000 sampai 1,5 juta terjadi di Indonesia, dimana 2.500 di antaranya berakhir dengan kematian. Angka aborsi di Indonesia diperkirakan mencapai 2,3 juta pertahun. Sekitar 750.000 diantaranya dilakukan oleh remaja. ${ }^{(8)}$. Hal itu terbukti dari banyak penelitian menyatakan tingginya angka aborsi yang tidak aman sehingga menyebabkan kematian oleh karena kurangnya pengetahuan remaja putri terhadap bahaya aborsi. Dari data yang didapatkan, menyatakan bahwa jumlah aborsi di 
Indonesia dilakukan oleh 2 juta orang tiap tahun, dari jumlah itu, 70.000 dilakukan oleh remaja putri yang belum menikah. Di Indonesia masih banyak perempuan yang melakukan aborsi, hal ini dapat dilihat dari data rumah sakit Dr. M. Haulussy tahun 2014 dengan jumlah aborsi sebanyak 36 orang diantaranya 25 orang melakukan abortus provocatus murni, setengahnya dilakukan oleh remaja produktif dan 11 orang melakukan abortus provocatus karena kegagalan alat kontrasepsi suntikan dan pil KB. ${ }^{(9)}$.

\section{Metode Pengabdian}

Kegiatan pengabdian kepada masyarakat dilaksanakan di SMA Negeri 1 Kairatu, pada bulan Februari 2020. Sasaran dari kegiatan pengabdian masyarakat ini adalah para siswa berada di lokasi penelitian. Kegiatan pengabdian ini berupa penyuluhan mengenai bahaya abortus menggunakan media leaflet, laptop, LCD, kuesioner dan speaker. Kegiatan pengumpulan data akan dilakukan dengan pretest dan post-test. Teknik pengumpulan data yang digunakan adalah teknik sampling aksidental yaitu siapa saja yang secara kebetulan bertemu dengan peneliti dapat digunakan sebagai sampel penelitian sesuai dengan kriteria inklusi dan eksklusi. Dalam kegiatan pengabdian masyarakat ini pengolahan dan analisis data menggunakan analisis univariat, hasil kuesioner yang didapatkan akan di tabulasi kemudian di analisis secara manual dan dibuatkan pembahasan.

\section{Hasil dan Pembahasan}

\section{A. Hasil}

\section{Hasil Pre-test dan Post-test Pengetahuan Siswa Tentang Bahaya Abortus}

Dari hasil data penelitian menunjukan bahwa adanya peningkatan pengetahuan siswa tentang bahaya abortus sebesar 92\%. Pengetahuan siswa mengenai bahaya abortus yang benar saat pre-test sebesar 20\%, setelah dilakukan penyuluhan mengenai bahaya abortus, sampel mendapatkan pemahaman dan pengetahuan sehingga nilai post-test meningkat sebesar 92\%. Data selengkapnya dapat dilihat pada tabel 1 .

Tabel 1. Hasil Pre-test dan Post-test Pengetahuan Siswa Tentang Bahaya Abortus

\begin{tabular}{ccccccc}
\hline \multirow{2}{*}{ No } & \multicolumn{3}{c}{ Pre-test } & \multicolumn{3}{c}{ Post-test } \\
\cline { 2 - 7 } & Pengetahuan & $\mathrm{f}$ & $\%$ & Pengetahuan & $\mathrm{f}$ & $\%$ \\
\hline 1 & Baik & 5 & 20,0 & Baik & 23 & 92,0 \\
2 & Kurang & 20 & 80,0 & Kurang & 2 & 2,0 \\
\hline & Jumlah & 25 & 100,0 & Jumlah & 25 & 100,0 \\
\hline
\end{tabular}

\section{B. Pembahasan}

Pada kegiatan ini rendahnya pengetahuan siswa dipengaruhi oleh ketidaktahuan tentang bahaya abortus dan terjebak dalam hal pergaulan bebas. Hal ini akan menganggap hal yang biasa dan angka abortus akan terus bertambah. Siswa penting mendapatkan pengetahuan mengenai bahaya abortus mengingat dampak abortus dapat menurunkan kualitas SDM di Indonesia. 
Dalam kegiatan pengabdian ini siswa aktif dalam mengikuti kegiatan penyuluhan dari awal dilaksanakan sampai akhir dilaksanakan. Peserta pengabmas aktif dalam sesi tanya jawab. Kegiatan pengabmas ini selain memberikan penambahan pengetahuan dan wawasan pada siswa mengenai bahaya abortus. Sebelum dilakukan penyuluhan dilakukan pre-test tentang bahaya abortus yang kuesionernya disebarkan oleh mahasiswa lalu dilakukan sesi penyuluhan degan memberikan leaflet lalu memulai materi penyuluhan yang dibawakan oleh mahasiswa. Setelah sesi materi tiba sesi tanya jawab dengan menggunakan metode diskusi aktif yang dijawab oleh dosen. Setelah sesi diskusi mahasiswa menyebar kuesioner kembali untuk melakukan evaluasi pengetahuan pada siswa. Kemudian hasil data dibuatkan tabulasi dan dilakukan analisis data menggunakan hitungan manual lalu hasil hitungan manual dideskripsikan.

Dengan adanya penyuluhan ini maka pemahaman dan wawasan siswa tentang bahaya abortus dapat meningkat dan siswa dapat menghindari pergaulan bebas karena negara yang maju akan tercipta dari generasi muda yang cerdas.

\section{Simpulan dan Saran}

Berdasarkan data yang diperoleh mendapatkan hasil adanya peningkatan pengetahuan siswa tentang bahaya abortus sebesar $92 \%$. Sehingga perlu dilakukan penyuluhan serta pelatihan secara menyeluruh dan berkala oleh tenaga kesehatan kepada siswa dan masyarakat dalam memberikan edukasi mengenai bahaya abortus. Dan dengan kegiatan pengabdian ini diharapkan dapat menyadarkan siswa tentang bahaya abortus dan lebih selektif dalam memilih pergaulan agar terhindar dari hal yang tidak diinginkan.

\section{Daftar Pustaka}

1. Susanto T, dkk. Prevalence Of Factors Related To Active Reproductive Health Behavior: a crosssectional study Indonesian adolescent. Epidemiology and Health. 2016; 38:e2016041:1-10.

2. Azwar, A. Kesehatan Reproduksi Remaja di Indonesia (Adolescent Reproductive Health in Indonesia), unpublished paper presented at the : National Congress of Epidemiology IX in Jakarta, 8 Nopember 2000.

3. Sarwono W., Sarlito. Apakah Seks Itu?. PT Bharata Karya Aksara. Jakarta.1986

4. De Lamater, John dan Sara M. Moorman. Sexual Behavior in Later Life. Journal of Aging and Health. 2007. 20 (10): 1-25.

5. Saifuddin, A. B. Panduan Praktis Pelayanan Kesehatan Maternal dan Neonatal. Jakarta : Yayasan Bina Pustaka Sarwono Prawirohardjo, 2006.

6. Nurhidayah DC. Hubungan Tingkat Pendidikan Dengan Respon Terhadap Kehilangan Pada Pasien Abortus. Purwokerto: FKIK; 2008.

7. Sneeringer KR. Billings DL. Roles Of Pharmacists In Expanding Access To Safe And Effective Medical Abortion In Developing Countries. Journal of public health policy Vol. 33, 2, 218-229.

8. Malanda N. Konsep Diri Remaja Yang Melakukan Aborsi. Depok: FPUG; 2012.

9. Anonim. Gugur Kandungan. Tersedia pada : http://id.wikipedia.org/wiki/gugurkandungan 